\title{
Interactive comment on "Comparing the performances of WRF QPF and PERSIANN-CCS QPEs in karst flood simulations and forecasting with a new Karst-Liuxihe model" by Ji Li et al.
}

\section{Anonymous Referee \#2}

Received and published: 24 September 2019

In this manuscript, the authors tried (1) to compare the performance of WRF QPF and PERSIANN-CCS QPEs and (2) to develop a new Karst-Liuxihe model. I agree with Reviewer 1 that it isn't convincing that the proposed new model can address the challenges of hydrological simulation in Karst areas. In addition, it isn't clear to how to add the karst mechanism into the Liuxihe model, and for example, regarding the karst water-bearing media simplification, it should be documented how to deal with this issue in the original model and how to improve it in the new model (described as equations or parameters). Also, I agree with Reviewer 1 that this manuscript isn't concise, especially too long abstract and introduction. In this manuscript, the authors tried to interpret too 
technique report. Therefore, I don't think that the current version is suitable to be published in this journal. Detailed comments 1 . In Line 40, the authors states "to reflect the true conditions of rainfall-runoff", and what is "true conditions"? Does the original model describe not true conditions? 2. In Lines 77-78, some references for "a few studies" are required. 3. In Line 261, what's the meaning of "grid gauges"? 4. On the model simulating, it isn't clear how to obtain the information on karst fissure width and how to set the initial condition such as soil moisture. 5. In Lines 599-600, the authors introduced that total 30 floods were chose from 1982-2013 for verification, i.e. about 1 flood per year. The objective of this manuscript is flood forecasting, so it is better to choose more floods and evaluate the model according to the flood forecasting criteria. In addition, in Lines 600-60, I guess that the model used in (Li et al., 2019) isn't the new model and those results only implied the effectiveness of another model. Therefore, the sentences shouldn't be there. 6. In Figures 10-16, what is the unit of $\mathrm{x}$-axis? h-1 or h?

Interactive comment on Hydrol. Earth Syst. Sci. Discuss., https://doi.org/10.5194/hess-2019285, 2019. 